\title{
Dementia Caregiving: The Role of the Primary Care Physician
}

\author{
Carole A. Cohen, Dorothy Pringle, Linda LeDuc
}

\begin{abstract}
Background: Family and friends play an important role in caring for individuals with dementia living in the community. In preparation for the Canadian Consensus Conference on Dementia held in Montreal, Canada in February 1998, the subject of dementia caregiving was reviewed in order to provide primary care physicians with some guidelines for their practice. The review was updated in June 2000 in preparation for this article. Method: Pertinent English-language publications and resources from the Alzheimer Society of Canada were reviewed from 1985 onwards. Findings related to the consequences of caregiving, services for caregivers and recommendations regarding the role of the primary care physician were reviewed. Findings: Dementia caregivers experience many positive and negative consequences of caregiving. Some comprehensive services for caregivers have been shown to delay institutionalization and reduce negative consequences of caregiving. The primary care physician has a role to play in working with families and should address the following issues: 1) education about dementia; 2) psychological support for caregivers; 3) assistance mobilizing caregiver social support networks. Conclusion: Primary care physicians have an important role to play in acknowledging and supporting the caregiving provided by family and friends to individuals with dementia.
\end{abstract}

RÉSUMÉ: Les soins aux déments: le rôle du médecin de première ligne. Introduction: La famille et les amis jouent un rôle important quant aux soins prodigués aux individus atteints de démence qui vivent dans la communauté. Lors de la préparation de la conférence canadienne de consensus sur la démence tenue à Montréal, Canada, en février 1998, le sujet des soins aux déments a été révisé afin de fournir aux médecins de première ligne des lignes directrices pour leur pratique. Cette revue a été mise à jour en juin 2000 pour préparer cet article. Méthode: Les publications pertinentes en anglais ont été révisées depuis 1985. Les observations reliées aux conséquences chez les aidants, aux services qui leur sont offerts et les recommandations sur le rôle du médecin de première ligne ont été révisées. Observations: Les aidants éprouvent plusieurs conséquences positives et négatives de ce rôle. Il a été démontré que certains services offerts aux aidants naturels retardent l'institutionnalisation et réduisent les conséquences négatives chez les aidants. Le médecin de première ligne a un rôle à jouer auprès des familles et devrait se préoccuper des aspects suivants: 1) l'éducation sur la démence; 2) le soutien psychologique aux aidants; 3) l'assistance pour leur procurer le soutien de réseaux sociaux. Conclusion: Les médecins de première ligne ont un rôle important à jouer pour accorder aux aidants naturels, parents et amis d'individus atteints de démence, reconnaissance et soutien.

Can. J. Neurol. Sci. 2001; 28: Suppl. 1 - S72-S76

This paper examines the responsibilities assumed by family caregivers in the care of their relatives who suffer from dementia, the effect of these responsibilities on the health and well-being of the caregivers and the role that family physicians can and should play in assisting them to manage these situations. A number of authors have described what they believe the family physicians' role should be and these positions are summarised. The findings reviewed were retrieved via computerized searches from 1985 onwards of MEDLINE, Psychinfo and Ageline, and reference lists and guidelines issued by relevant professional and advocacy organizations. The recommendations were reviewed at the Canadian Consensus Conference on Dementia in 1998. This background paper was prepared for that conference and was updated in June 2000.

\section{The Role of Caregivers in Dementia Care}

Canada is fortunate in having recent and reliable epidemiologic data on the prevalence of people with dementia and on the characteristics of their informal caregivers. Approximately half of the individuals suffering from dementia in

From the Department of Psychiatry, University of Toronto (CAC), Faculty of Nursing, University of Toronto (DP), Alzheimer's Society of Canada (LLD) Toronto, Ontario, Canada

Reprint requests to: C.A. Cohen, Sunnybrook and Women's College Health Sciences Centre, Room F307 - 2075 Bayview Avenue, Toronto, Ontario, Canada M4N 3M5 
Canada live in the community ${ }^{1}$ and family or friends care for approximately $94 \%$ of them. Spouses represent $36 \%$ of these caregivers, daughters $28 \%$ and sons $9 \%$. The majority of caregivers are women, the wives and daughters of the affected individuals.

Caregivers are involved in a variety of caregiving responsibilities and caregiver reports have been found to be as reliable as objective measures of cognitive and functional decline. ${ }^{2}$ Family caregivers play a vital role in providing direct day-to-day care to dementia patients. This role changes as the patient becomes more cognitively impaired and needs more assistance and supervision. Clinicians often rely on caregivers to monitor for changing patient status, for the onset of new symptoms and for implementation of treatment plans. Individuals with dementia who have no family to assist them or whose family members report high caregiver burden are more likely to move into institutions earlier in the course of their illness. Even after the patient with dementia moves into an institution, family members stay actively involved in the vast majority of cases to assist with care and decision-making.

\section{CONSEQUENCES FOR FAMILY CAREGIVERS}

The care provided by family and friends, although a major factor in the health and social system, is often hidden and poorly recognized. Increasingly, it is being suggested that the vital role played by the caregivers be acknowledged and supported.

\section{Negative consequences}

In recent years, a great deal has been learned about the stress and burden experienced by those caring for someone with dementia. Some caregivers adapt to the challenges of caregiving while others report increased stress as the disease progresses. Many caregivers find it particularly challenging that the patient often cannot thank them for their help and might resent some of the decisions the caregiver has to make. Up to $50 \%$ of caregivers experience significant psychiatric symptoms (anxiety and depression) during the course of their caregiving career and psychotropic drug use is high among this group. ${ }^{3}$ Dementia caregivers perceive their general health to be worse than others. Spousal caregivers exhibit impaired immune system functioning compared to noncaregivers ${ }^{4}$ which may put them at increased risk for health problems. Caregivers of dementia patients also use services billed by psychiatrists and internal medicine specialists more than a comparable group of family caregivers. ${ }^{5}$

Low income, high perceived stress, low life satisfaction and poor self-esteem/mastery are all risk factors for negative health outcomes among caregivers. In addition, problem behaviours of the demented patient, severity of their cognitive impairment and limitations in their self-care all predict higher caregiver distress. Factors that seem to lessen caregiver burden include practical and emotional support from family and friends. Caregivers who view their role as satisfying and who use coping responses characterized by problem solving and seeking information report less distress. ${ }^{4}$ There may also be differences among subgroups of caregivers, with spouses affected differently than children, and women and men caregivers reacting differently to the challenge. ${ }^{6}$ Those caring for young dementia patients ( $<55$ years) may be at increased risk of negative consequences of caregiving.

\section{Positive Consequences}

Less has been written about the positive aspects of caregiving; however, caregivers do report a sense of satisfaction in a job well done, a sense of mastery in learning new skills and a feeling of accomplishment in keeping a loved one at home. Caregivers who report these experiences may be less likely to use formal support services or to desire nursing home placement for their dependants. ${ }^{7}$

\section{SERVICES AND INTERVENTIONS FOR CAREGIVERS}

A variety of services and interventions have been developed to assist caregivers in dealing with their role and to alleviate the negative consequences of caregiving. While there has been a great deal of research examining the effectiveness of these interventions, methodological issues have plagued the research from the start and complicated the findings. Knight et $\mathrm{al}^{8}$ reviewed the interventions and concluded that “... respite interventions and individual psychosocial interventions are moderately effective compared with treatment as usual or uncontrolled use of community services. Group psychosocial interventions are less effective in the same comparison" (p.247). A recent review by Roberts et $\mathrm{al}^{9}$ confirmed these findings. Respite programs and day programs kept dementia patients in the community longer. Counselling for caregivers not only increased the time spent in the community by individuals with dementia but also increased psychosocial adjustment for caregivers with poor coping skills. Zarit et $\mathrm{al}^{10}$ stress that "studies in which ... families received adequate amounts of help showed more consistently positive outcomes" (p.165).

Respite interventions include specialized dementia day care, in-home respite programs and out-of-home respite admissions, all of which are available to varying degrees across Canada. Despite their effectiveness, these respite services are consistently under-utilized by caregivers. ${ }^{1}$ The role of family physicians in recommending these services and facilitating their utilization is not well studied.

Individual psychosocial interventions might include a variety of individual psychotherapies provided by practitioners including family physicians. They might also include specific training programs such as those designed to teach caregivers problem-solving skills. Examples of group psychosocial interventions include support groups run by professionals and self-help groups, many of which are sponsored by local Alzheimer Society chapters.

Comprehensive support programs comprising several of these elements are often offered at specialized dementia centres. Brodaty et $\mathrm{al}^{11}$ developed a comprehensive program which focuses on three types of interventions: 1) education about dementia; 2) psychological support for the caregiver with a focus on stress management, communication, self care and grief work; 3) assistance to caregivers to develop their social support system - family, community and professional. Brodaty et al were able to demonstrate a delay in institutionalization of dementia patients when caregivers were enrolled in their program. From their research they conclude that these interventions are probably more effective in the early to middle stages of the dementing illness.

Mittelman et al ${ }^{12,13}$ developed an intervention that combined individual and family counselling sessions "with primary focus 
on increasing support for the spouse-caregiver from other family members". These sessions also provided education about patient behaviour problems and how to deal with them. Counsellors emphasized the need for caregivers to care for themselves. Caregivers attended weekly support groups and could get ad hoc consultation at any time via telephone.

This program allowed for continuous support for the primary caregiver as long as was needed. The researchers noted that the effects of the intervention might not be immediate but take some time to be helpful to the caregivers. They reported that their intervention delayed institutionalization of dementia patients and reduced the prevalence of depression among the spouse caregivers.

Most recent research has documented that treatments aimed specifically at the dementia patient may also benefit the caregiver indirectly. Studies are beginning to explore the effects of cognitive enhancers on the dementia patient and caregiver burden. Behavioural interventions designed to reduce depression in dementia patients have also been shown to reduce caregiver burden. $^{14}$

\section{Caregiver EXPeCtations}

Lennox ${ }^{15}$ has reviewed the studies examining how caregivers for dementia patients perceive their interactions with family physicians. Caregivers repeatedly stated they wanted recognition for the importance of their caregiving role. They often did not feel they received adequate information from their family physicians over the course of the dementing illness. Families and affected individuals wanted to have the diagnosis of dementia communicated to them. Caregivers wanted assistance with behavioural problems, referrals to social agencies and regularly scheduled visits with family MDs.

\section{THE ROLE OF THE PRIMARY CARE PHYSICIAN}

Several studies have documented that family physicians do not always have the knowledge and skills to effectively deal with dementia patients and their caregivers. ${ }^{16,17}$ Given the aging of the population and increased emphasis on community care, it seems prudent for physicians to consider how they can best support dementia caregivers.

Several authors stress the need for physicians to work with their patients in the context of the family and the need to work as partners with caregivers. ${ }^{18,19}$ Cohen $^{730}$ recommends the assessment of four domains: the patient, individual family caregivers, the way the entire family does or does not work together, and available community resources. Others emphasize the importance of the family physician providing ample opportunity for the caregiver to talk, the establishment and maintenance of alliances with families and the need for home visits to see first-hand how things are going. ${ }^{20-23}$

The Alzheimer Society of Canada Family Physician CME Project Report ${ }^{15}$ summarizes a number of core competencies for family physicians working with dementia patients. These include effective communication skills, knowledge of community resources useful in assessment and management of dementia, provision of ongoing care, ability to collaborate with other professionals and agencies, and awareness of caregiver concerns.
Physicians will probably not be able to provide all the support and assistance caregivers need but will need to know where to refer caregivers so that they can get help as they need it. To this end, caregivers will need to be seen regularly by family physicians, not only to acknowledge their important role but also to assess their needs. This may be more complicated when the caregiver has a different physician than the dementia patient. Particular care must be taken in these situations for collaboration between family physicians.

There may be particular times in the dementia patient's illness when caregivers need more frequent and intensive support: at the time of diagnosis; when the patient can no longer be left alone; when nursing home placement is being considered; and when the patient enters the last phase of the illness.

Many of the recommendations regarding the role of the family physician in supporting dementia caregivers can be subsumed under the three dimensions used by Brodaty et $\mathrm{al}^{11}$ in designing their comprehensive program: (a) education, (b) psychological support and (c) assistance with social support.

\section{a) Education}

\section{i) The diagnosis and its meaning}

The family physician may be the clinician who conveys the diagnosis of dementia to the patient and his/her family. This requires sensitivity, clarity of language and sufficient time for the family members to hear what is being said. The information should include the fact that memory loss is not normal but is the result of disease processes; and that while it is not possible to be absolutely certain what the future will hold, dementias are progressive in nature. ${ }^{24}$ Caregivers need to understand that the dementia will affect the patient in many ways, i.e., changes in personality, increased risk for delirium and medical illness. Families also require information about the genetics of the disease and the risks to other family members, ${ }^{25}$ the implications of the disorder for activities such as driving, ${ }^{22}$ and that treatments and other strategies are available to assist with the changes in behaviour, cognition and ability to perform the activities of daily living that attend the disorder. ${ }^{22,24}$

\section{ii) Management of behavioural changes related to the dementia}

The American Psychiatric Association ${ }^{22}$ suggests that the caregivers should be educated on how to alleviate behavioural symptoms and provided with a set of principles to guide them in dementia care. These include:

a) keeping requests and demands relatively simple and avoiding overly complex tasks that might lead to frustration;

b) avoiding confrontation and deferring requests if the patient becomes angered;

c) remaining calm, firm and supportive if the patient becomes upset;

d) being consistent and avoiding unnecessary change;

e) providing frequent reminders, explanations and orientation cues;

f) recognizing declines in capacity and adjusting expectations appropriately; 
g) bringing sudden declines in function and the emergence of new symptoms to professional attention.

Behavioural logs completed by caregivers may be useful to provide the family physician with information regarding the current problem behaviours. Caregivers can then be educated about the cause of the behaviours and how to best cope with them. Medications may also be helpful to treat the behavioural problems of dementia patients.

\section{iii) Advanced planning}

Caregivers will require information about what the future is likely to bring as the dementia progresses. ${ }^{21}$ This will include information about financial and legal issues such as Wills, Powers of Attorney, driving and advance directives. ${ }^{26-28}$ When the family begins to confront the need for institutionalization, they will need information and assistance with the placement process. As the disease progresses further, the need to discuss end-of-life care will likely arise. ${ }^{26}$ Most family members, as do most physicians, ${ }^{27}$, prefer that their relatives receive what Volicer et $\mathrm{al}^{28}$ refer to as fifth-level care, i.e., all measures to keep the patient comfortable including medication for chronic illness and pain, but no treatment of acute illnesses such as pneumonia, no resuscitation and no use of tube feeding of the patient who cannot or will not eat.

\section{b) Psychological support}

It is widely recommended that caregivers be seen regularly to assess whether they are depressed and how they are coping. 3,4,22,23 Caregivers might need individual counselling or assessment and treatment of psychiatric disorders. They might benefit from assistance individually or in groups to address problem solving or coping skills. They need to be able to talk about their frustrations and grief, not only when the dementia patient is being cared for by them, but when the patient moves to an institution or dies.

\section{c) Assistance with social support}

Authors suggest that clinicians evaluate the caregiver's social network and their willingness to elicit help from this network. $^{20,29}$ This network might include family and friends as well as formal supports in the community. Ethnic and cultural issues should be explored to better understand what help might be acceptable to the caregiver(s). Knowledge of family functioning (i.e., co-operation, conflict and health of other family members) is helpful in supporting caregivers. Often it is a challenge to get caregivers to ask for help or accept help from others. Caregivers may require individual counselling to help them understand the need for help and develop the skills to ask. They may need "prescriptions" from their physician for support groups or other types of interventions. They may require family counselling to help elicit assistance from those close to them.

Caregivers can be referred to the Alzheimer Society for education and for access to the many support services they provide..$^{20,22,23,25}$ Family caregivers also require information and referral to support groups and respite services (day care, in-home services). Referrals to specialists to manage specific problems may also be warranted. Caregivers may need a great deal of encouragement to use these services despite their reported efficacy. Family physicians are in a unique position to encourage and facilitate these referrals.

\section{RECOMMENDATIONS}

Based on the literature, the following are recommendations for the role of the primary care physician in working with caregivers of those suffering from dementia. They were approved as $\mathrm{B}$ level recommendations ${ }^{30}$ at the Canadian Consensus Conference on Dementia.

\section{RECOMMENDATIONS FOR PRIMARY CARE PHYSICIANS WORKING WITH DEMENTIA PATIENT CAREGIVERS}

1. Acknowledge the important role played by the caregiver in dementia care. Work with caregivers and their families on an ongoing basis, from the diagnosis of dementia until the death of the patient. Schedule regular appointments for patients and caregivers together and alone. (Level III evidence)

2. Educate patients and families about the disease and appropriate modifications that must be made day to day in the home environment and in communicating and interacting with the dementia patient. (Level III evidence)

3. Evaluate caregiver coping strategies and encourage caregivers to care for themselves, using health promotion strategies and stress reduction strategies. (Level III evidence)

4. Assess the caregiver's social support system and help caregivers rally support for themselves from appropriate family members and friends. (Level III evidence)

5. Screen for caregiver burden, psychiatric problems and health problems by regularly meeting with caregivers and asking specific questions about their health and caregiver strain. Offer caregivers treatment for these problems (individual psychotherapy or medications as indicated) or refer to appropriate specialists or services. (Level III evidence)

6. Refer caregivers to appropriate community services for dementia care (i.e., day care, respite care, local Alzheimer Society, long-term care settings) realizing that it may take encouragement and time for these services to be used. If available, refer patients to specialized dementia programs that offer comprehensive treatment programs. (Level I evidence)

7. Discuss legal and financial issues and obtain appropriate help for caregivers and families if you are not comfortable with these issues. (Level III evidence)

8. Assess and treat the behavioural problems of dementia on an ongoing basis. If needed, refer caregivers to the Alzheimer Society for information on modifying behavioural problems. (Level III evidence).

\section{ACKNOWLEDGEMENTS}

The authors thank Dr. J. Feightner for assistance in the preparation of this manuscript. The authors acknowledge the participants of the Canadian Consensus Conference on Dementia held in Montreal, February 27 and 28, 1998, where this paper was presented.

\section{REFERENCES}

1. Canadian Study of Health and Aging Working Group. Patterns of caring for people with dementia in Canada: the Canadian Study of Health and Aging. Can J Aging 1994; 13:470-487.

2. O'Connor DE, Pollitt PA, Brook CPB, Reiss BB. The validity of informant histories in a community study of dementia. Int $\mathbf{J}$ Geriatr Psychiatry 1989; 4:203-208.

3. Schulz R, O'Brien AT, Bookwala J, Fleissner K. Psychiatric and physical morbidity effects of dementia caregiving: prevalence, 
correlates and causes. Gerontologist 1995; 35:771-791.

4. Haley WE. The family caregiver's role in Alzheimer's disease. Neurology 1997; 48 Suppl 6:S25-S29.

5. Baumgarten $\mathrm{M}$, Battista RN, Infante-Rivard $\mathrm{C}$, et al. Use of Physician Services among Family Caregivers of Elderly Persons with Dementia. J Clin Epidemiol 1997; 50(11):1265-1272.

6. Grunfeld E, Glossop R, McDowell I, Danbrook C. Caring for elderly people at home: the consequences to caregivers. Can Med Assoc J 1997; 157(8):1101-1104

7. Cohen CA, Pushkar Gold D, Shulman KI, Zucchero CA. Positive Aspects in Caring: An Overlooked Variable in Research. Can J Aging 1994; 13(3):378-391.

8. Knight BG, Lutzh AA, Macofsky-Urban F. A meta-analytic review of interventions for caregiver distress: recommendations for future research. Gerontologist 1993; 33:240-248.

9. Roberts J, Browne G, Gafni A, et al. Specialized Continuing Care Models for Persons with Dementia: A Systematic Review of the Research Literature. Can J Aging/La Revue canadienne du viellissement 2000; 19(1):106-126

10. Zarit SH, Gaugler JE, Jarrott SE. Useful Services for Families: Research Findings and Directions. Int J Geriatr Psychiatry 1999; 14:165-181.

11. Brodaty H, Gresham M, Luscombe G. The Prince Henry Hospital dementia caregivers'training programme. Int J Geriatr Psychiatry 1997; 12:183-192.

12. Mittleman MS, Ferris SH, Shulman E, et al. A comprehensive support program: effect on depression in spouse-caregivers of $\mathrm{AD}$ patients. Gerontologist 1995; 35:792-802.

13. Mittleman MS, Ferris SH, Shulman E, Steinberg G, Levin B. A family intervention to delay nursing home placement of patients with Alzheimer's disease. JAMA1996; 276- No.21:1725-1731

14. Teri L, Logsdon RG, Uomoto J, McCurry SM. Behavioral Treatment of Depression in Dementia Patients: A Controlled Clinical Trial. J Gerontolog Psychol Sci 1997; 52B(4):159-166.

15. Lennox A. Family Physician CME Project Report Phase 1. The Alzheimer Society of Canada 1997.

16. Rubin SM, Glasser ML, Werckle MA. The Examination of Physicians' Awareness of Dementing Disorders. JAGS 1987; 35:1051-1058.

17. Barret JJ, Haley WE, Harrell LE, Powers RE. Knowledge About
Alzheimer's disease Among Primary Care Physicians, Psychologists, Nurses, and Social Workers. Alzheimer's disease and Associated Disorders 1997; 11(2):99-106.

18. McWhinney IR. ATextbook of Family Medicine. Oxford University Press 1997; 229-257.

19. Council on Scientific Affairs of the American Medical Association. Physicians and family caregivers: a model for partnership. JAMA 1993; 269:1282-1284.

20. Cohen D. A primary care checklist for effective family management in the Medical Clinics of North America: Management of Patients with Alzheimer's and Related Disorders. Eisdorfer C, Olsen EJ, Eds. 1994; 78:795-809.

21. Alzheimer Society of Canada. Guidelines for Care. The Alzheimer Society of Canada 1992.

22. American Psychiatric Association. Practice guidelines for the treatment of patients with Alzheimer's disease and other dementias of late life. Am J Psychiatry 1997; 154 Suppl 5.

23. Small GW, Rabins PV, Barry PP, et al. Diagnosis and Treatment of Alzheimer's disease and Related Disorders: consensus statement of the American Association for Geriatric Psychiatry, The Alzheimer's Association and the American Geriatrics Society. JAMA1997; 278:1363-1371.

24. Alzheimer Society of Canada. Tough Choices: Ethical guidelines. The Alzheimer Society of Canada 1997.

25. Brodaty $\mathrm{H}$. The role of the GP in the management of Alzheimer's disease. Mod Med Aust 1996; February: 22-37.

26. McCarthy M, Addington-Hall J, Altmann D. The experience of dying with dementia: a retrospective study. Int $\mathrm{J}$ Geriatr Psychiatry 1997; 12:404-409.

27. Luchins DJ, Hanrahan P. What is appropriate health care for endstage dementia. JAGS 1993; 41:25-30.

28. Volicer L, Rheaume Y, Brown J, et al. Hospice approach to the treatment of patients with advanced dementia of the Alzheimer type. JAMA1986; 256:2210-2213.

29. Dunkin JJ, Anderson-Hanley C. Dementia caregiver burden - a review of the literature and guidelines for assessment and intervention. Neurology 1998; 51(Suppl1):S53-S60.

30. Canadian Task Force on the Periodic Health Examination. Canadian Guide to Clinical Preventative Health Care. Ministry of Supply and Services Canada 1994. 